\title{
Effect of Pore Water Salinity on Swelling Hehavior, and Mineralogical and Microstructural Properties of Bentonite-Sand Barrier Materials
}

\author{
Mohammed Alzamel, Mamadou Fall \\ Department of Civil Engineering / University of Ottawa \\ 161 Louis Pasteur, K1N 6N5, Ottawa, ON, Canada \\ Malza039@uottawa.ca; Mamadou.Fall@uottawa.ca
}

\begin{abstract}
The swelling properties of bentonite-sand material are critical parameters for designing the engineered barriers of radioactive waste repositories. In this study, the effect of the underground water salinity in the Guelph region in Ontario (Canada) on the swelling behaviour, and mineralogical and microstructural properties of compacted bentonite-sand mixture is investigated. Bentonite/sand samples with different mix ratios (20/80 and 70/30) are prepared. The samples are then immersed into water with different chemical compositions, including distilled water (DW, or the control), and a saline solution (Solution G) with a chemical composition similar to that of the deep underground water of Guelph. The total dissolved solids (TDS) of Solution $\mathrm{G}$ is $300 \mathrm{~g} / \mathrm{L}$ (pH 5.7). A series of different laboratory experiments and analyses have been conducted, such as one-dimensional free swell testing, $x$-ray diffraction (XRD) analysis, energy dispersive $\mathrm{x}$-ray spectrometry (EDS) and thermal analyses, to investigate the swelling characteristics, and mineralogical and microstructural properties of the bentonite-sand mixtures. The test results indicate that groundwater salinity has a significant impact on the swelling, mineralogical and microstructural characteristics of the barrier material. For a given initial dry density, the swell time and maximum swelling strain of the compacted bentonite-sand samples decrease with an increase in the amount of TDS. The XRD, EDS and thermal analyses detect some transformation of montmorillonite in the bentonite into illite as well as cation exchange processes.
\end{abstract}

Keywords: Swelling behavior, Deep geological repository, Mineralogical, Microstructural, Bentonite-sand mixture, Radioactive wastes.

\section{Introduction}

Nuclear power plants produce large amounts of radioactive waste every year that are detrimental to humans and the environment. Canada and other countries consider that the most appropriate solution is to construct deep geological repositories (DGRs) at depths of 300 to $1000 \mathrm{~m}$ for isolating and disposing radioactive waste. The safety of a DGR depends on the stability of the engineering barrier system (EBS) [1] and natural host rock. Bentonite is commonly proposed as the engineered barrier material in DGRs to minimize the risk of radioactive contamination of the surrounding environment.

Bentonite is a clay material that is composed of minerals in the smectite group. Bentonite has good engineering properties, such as low hydraulic conductivity, ability to retain radionuclides in the event of canister fail and high swelling potential; thus, it is an effective barrier material. Furthermore, its low permeability means that contaminants migrate primarily by molecular diffusion through barriers constructed of bentonite. However, compacting this type of clay mineral in a DGR might lead to mechanical damage of the EBS when it comes into contact with underground water due to the high swelling potential of pure bentonite. For this reason, bentonite is mixed with sand to reduce the swelling stress, so that it can be used as an effective component of artificial barriers [2-5]. These appropriate swelling characteristics or potential of bentonite-sand material is essential for ensuring the safety of a DGR [6].

However, these properties of bentonite-sand material can be significantly affected by the chemical composition of the fluid within its pores. This means that the interaction of the bentonite/sand barrier with aggressive fluids in the DGR could significantly change its good performance properties (e.g., swelling potential). This would negatively impact the long-term performance of bentonite-based materials as a barrier to radionuclide migration.

In Canada, it has been proposed to construct a DGR for low and intermediate-level radioactive waste in the Municipality of Kincardine (Ontario) at a depth of $680 \mathrm{~m}$. However, the groundwater in Ontario is highly saline at the 
depth of the proposed DGR. The total dissolved solids (TDS) range from 200,000 to 400,000 $\mathrm{mg} / \mathrm{L}$. Therefore, the groundwater might affect the overall safety of a DGR by influencing the swelling and mineralogical and microstructural properties of a bentonite-sand barrier [7].

The purpose of this paper is to investigate the effect of underground water salinity in the Guelph region on the swelling behaviour, and mineralogical and microstructural properties of compacted bentonite-sand with different mix ratios.

\section{Experimental Program}

\subsection{Materials}

MX-80 bentonite which originated from Wyoming, USA was used in the experiment, which contains $92 \%$ montmorillonite, and also quartz, calcite, and feldspar. Quartz sand (GS-20 silica sand) was used, which contains 99.99\% silica $\left(\mathrm{SiO}_{2}\right)$ and has a specific gravity of 2.6. The grain size of the quartz sand ranges from 0.2 to $1.9 \mathrm{~mm}$ (Figure 1). All of the bentonite particles passed through the No. 100 sieve $(0.150 \mathrm{~mm})$ and $98 \%$ passed through the No. 200 sieve $(0.075$ $\mathrm{mm}$ ) (Figure 1).

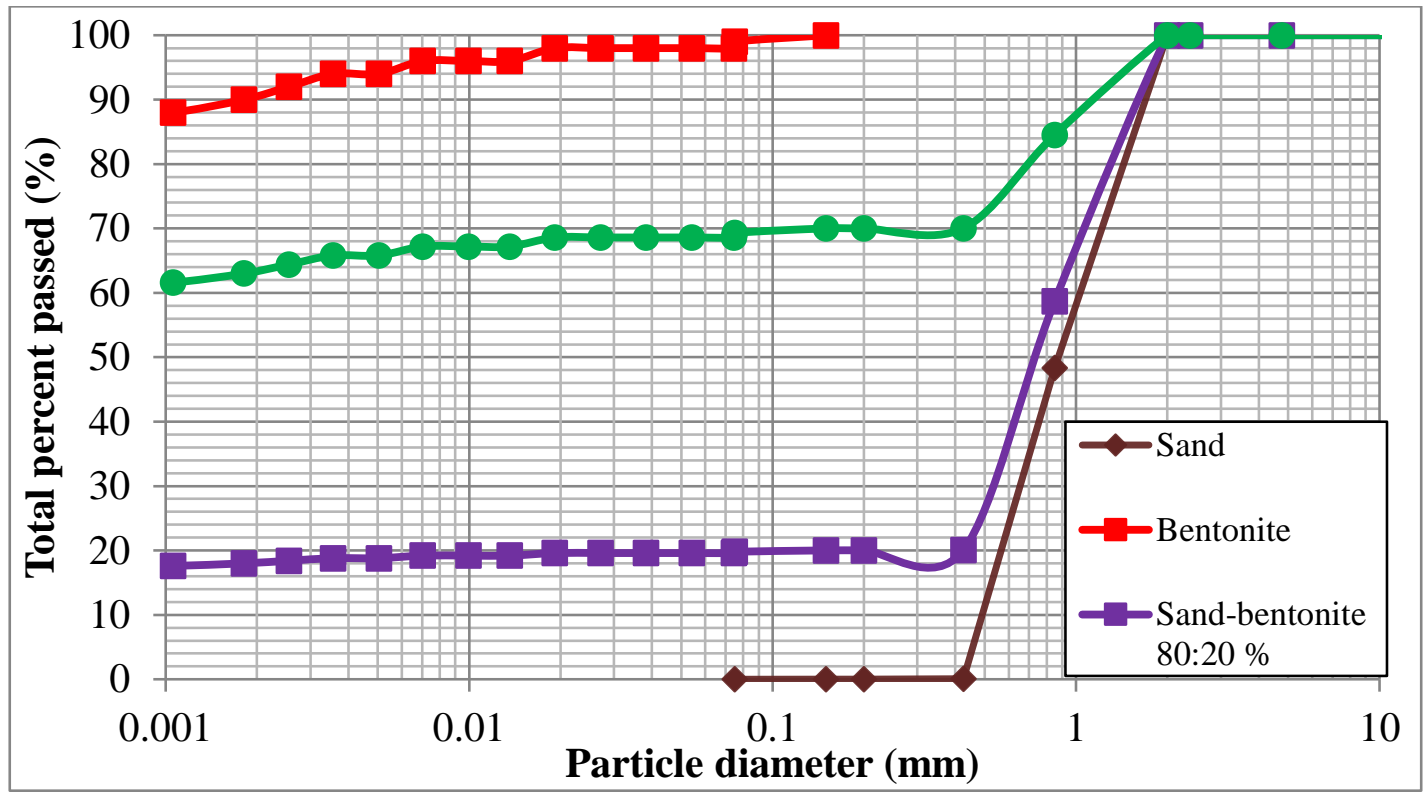

Fig. 1: Bentonite, sand and bentonite-sand (20:80 and 70:30) grain size distribution.

\subsection{Sample preparation and mix proportion}

The MX-80 bentonite and sand were oven-dried separately at $105^{\circ} \mathrm{C}$ for 24 hours and then mixed thoroughly at different weight ratios (20/80 and 70/20 bentonite-sand by weight). Samples of the mixtures were then blended with the required type and amount of water (distilled water (DW) or saline solution (Solution G)). The water content and initial dry density of each mixture were obtained by compaction testing (standard proctor compaction method, ASTM D698) with an automatic Proctor hammer [8]. For each mixture, the optimum water content and maximum dry density were determined based on the compaction curve or the plotted dry density versus moisture content (Figure 2). 


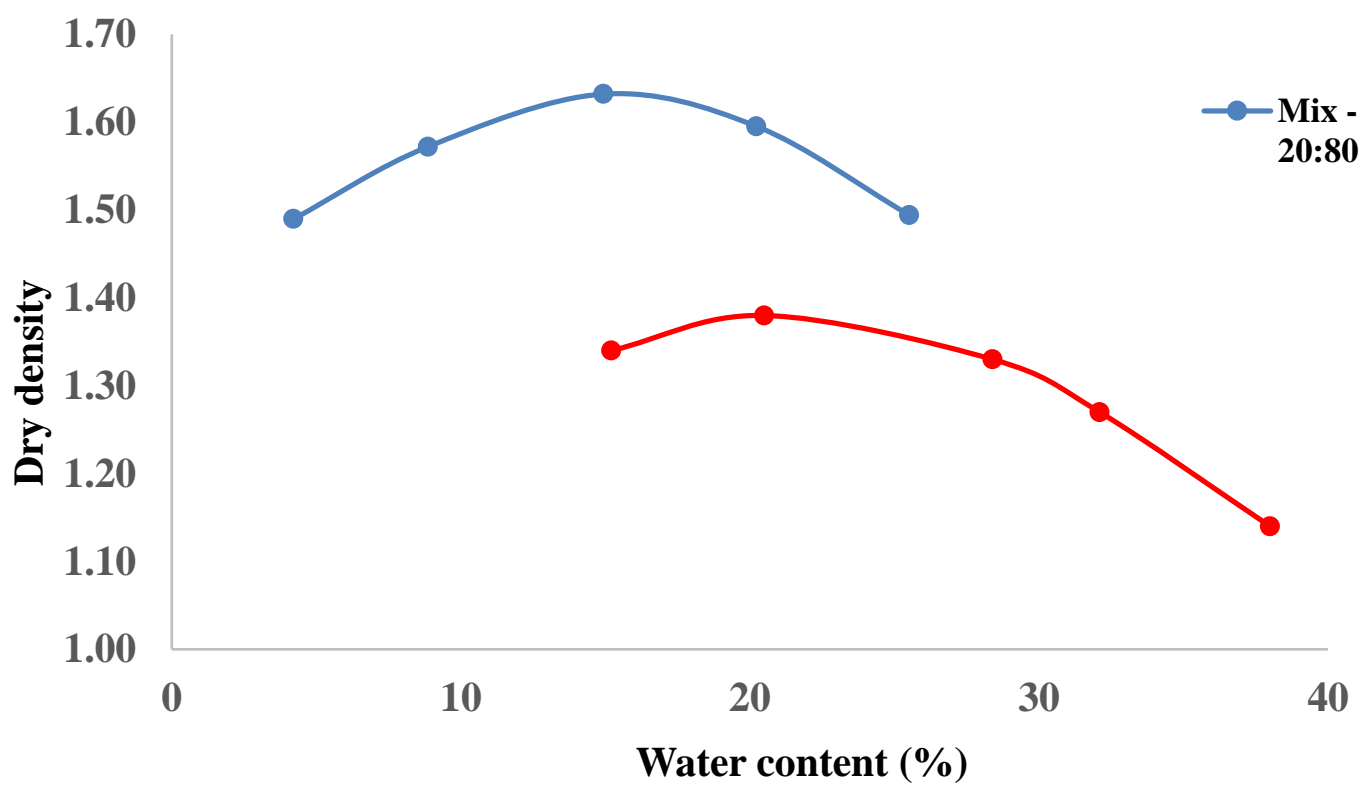

Fig. 2: Dry density versus moisture content (compaction curve) for bentonite-sand mixtures.

\subsection{Testing of samples}

\subsubsection{One dimensional free swell testing}

One-dimensional free swell testing was conducted by following ASTM standard D-4546-08. The samples were soaked in DW and Solution G respectively under approximately zero vertical pressure.

\subsubsection{X-Ray diffraction}

X-ray diffraction analyses were performed by using a Philips X'Pert diffractometer to determine the mineralogical changes in the bentonite after soaking in Solution G.

\subsubsection{Thermal analysis}

Thermal analysis was performed by using a thermal analyzer (TGA Q5000 V3.15 Build 263, University of Ottawa) under a nitrogen atmosphere. The powdered samples $\left(17-20 \mathrm{mg}\right.$ ) were heated to a temperature of $1000^{\circ} \mathrm{C}$ at a rate of $10^{\circ} \mathrm{C} / \mathrm{min}$ under nitrogen purge $(25 \mathrm{~mL} / \mathrm{min})$.

\subsubsection{X-Ray Microanalysis}

Energy dispersive spectroscopy (EDS) was performed by using an INCA-X-act energy dispersive x-ray spectroscope (Oxford Instruments, UK) to observe the changes in the microstructure of the bentonite samples and determine the chemical composition of the pure bentonite and bentonite-sand mixture immersed in DW or Solution G.

\section{Result and Discussion}

The results of the swelling tests (Figure 3) showed that the groundwater salinity significantly reduces the swelling potential of the bentonite-sand material regardless of the mix ratio. The XRD, EDS and TGA/DTG analyses showed that this reduction of the swelling potential is due to the mineralogical and chemical changes in the bentonite which were caused by immersion in Solution G. Indeed, there was the partial transformation of Na-montmorillonite into Ca, $\mathrm{Mg}$ montmorillonite and illite when the bentonite-sand mixtures were saturated in Solution G. This cation exchange may change the amount of swelling capacity. The Ca-montmorillonite and illite have a lower swelling capacity than Namontmorillonite. 


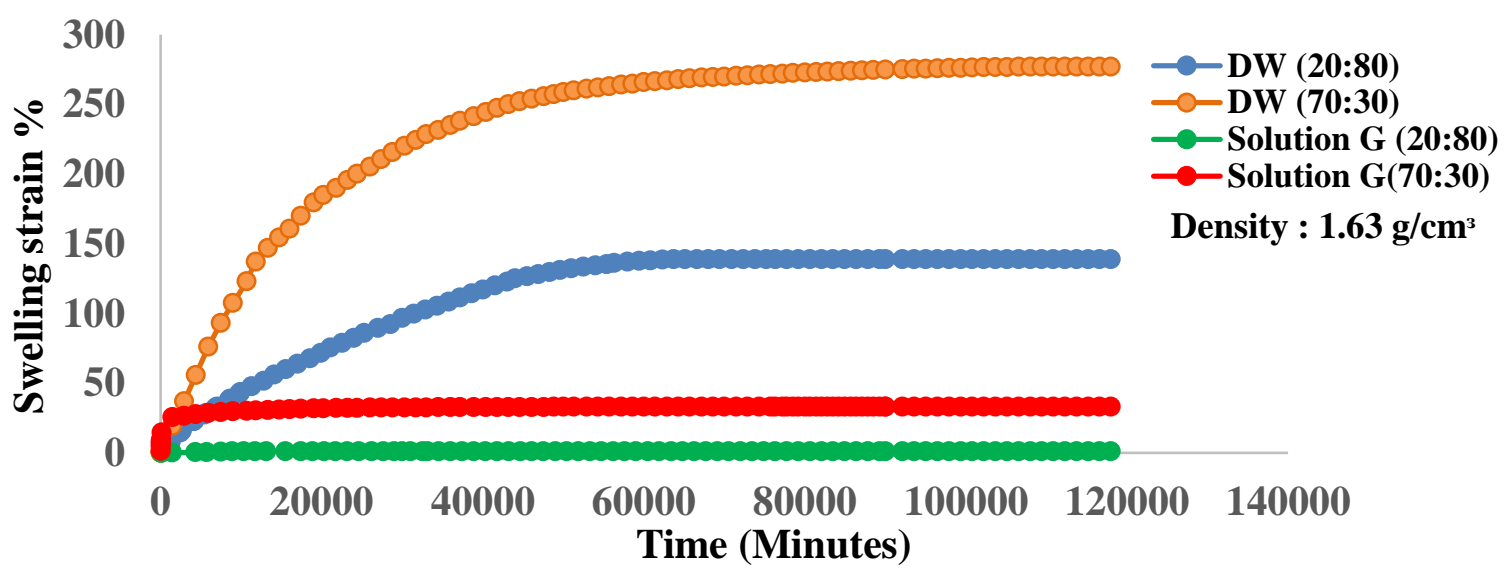

Fig. 3: Effect of DW and Solution G on swelling strain and swelling rate of bentonite-sand mixtures.

\section{Conclusion}

Laboratory experiments have been performed to investigate the effect of the chemical composition of deep groundwater in Guelph (Ontario, Canada) on the swelling potential of bentonite-sand material with different mix ratios (20/80 and 70/30) for use in a nuclear waste repository. The obtained results show that the salinity of the groundwater causes mineralogical, chemical and microstructural changes in the bentonite-sand material. The Na-bentonite tends to change from sodium ( $\mathrm{Na}$ ) to other types (i.e. $\mathrm{Ca}$ or $\mathrm{K}$ ) of bentonite depending on the cations present in the water solutions, which in turn, significantly reduces the swelling potential of the bentonite-sand regardless of the mix ratio. This issue should be taken into consideration to design a safe DGR in Ontario.

\section{Acknowledgement}

The authors would like to thank Natural Sciences and Engineering Research Council of Canada (NSERC) and the King Abdulaziz City for Science and Technology (KACST) for financially supporting this research.

\section{References}

[1] S. Sánchez González, "The swelling pressure of bentonite and sand mixtures," Master of Science Thesis. KTH Chemical Science and Engineering, 2013.

[2] H. Komine, K. Yasuhara, and S. Murakami, "Swelling characteristics of bentonites in artificial seawater," Canadian Geotechnical Journal, vol. 46, no. 2, pp. 177-189, 2009.

[3] M. V. Villar, and A. Lloret, "Influence of dry density and water content on the swelling of a compacted bentonite," Applied Clay Science, vol. 39, no. 1-2, pp. 38-49, 2008.

[4] Q. Wang, A-M. Tang, Y-J. Cui, P. Delage, B. Gatmiri, "Experimental study on the swelling behaviour of bentonite / claystone mixture," Engineering Geology, vol. 124, pp. 59-66, 2012.

[5] R. Proia, P. Croce, and G. Modoni, "Experimental Investigation of Compacted Sand-bentonite Mixtures," Procedia Engineering, vol. 158, pp. 51-56, 2016.

[6] D. I. Stewart, P. G. Studds, and T. W. Cousens, "The factors controlling the engineering properties of bentoniteenhanced sand," Applied Clay Science, vol. 23, no. 1, pp. 97-110, 2003.

[7] M. Jensen, T. Lam, D. Luhowy, J. McLay, B. Semec, R. Frizzell, "Ontario Power Generation's Proposed L\&ILW Deep Geologic Repository: An Overview of Geoscientific Studies," Canadian Geotechnical Conference, pp. 13391347, 2009.

[8] ASTM D698-02 2012, Standard Test Methods for Laboratory Compaction Characteristics of Soil Using Standard Effort (12400 ft lbf/ft3 (600 KN m/m3), vol. 15.09, Annual book of ASTM Standards, West Conshohocken, Pa, USA, 2012. 